\title{
'Set up to Fail'? How Welfare Conditionality Undermines Citizenship for Vulnerable Groups
}

\author{
Aaron Reeves* and Rachel Loopstra** \\ *International Inequalities Institute, London School of Economics and Political Science, London \\ E-mail: a.reeves@/se.ac.uk \\ **Department of Sociology, University of Oxford, Oxford \\ E-mail: rachel.loopstra@sociology.ox.ac.uk
}

Underpinned by the assumption that unemployed persons are passive recipients of social security, recent welfare reforms have increased benefit conditionality in the UK and introduced harsher penalties for failure to meet these conditions. Yet, conditionality may result in vulnerable groups disproportionately experiencing disentitlement from benefits, one of the rights of social citizenship, because they are, in some cases, less able to meet these conditions. Rising sanctions, then, may be the product of a disconnection between welfare conditionality and the capabilities of vulnerable claimants. To test this hypothesis, we evaluate whether sanctions are higher in areas where there are more vulnerable Jobseeker's Allowance claimants, namely, lone parents, ethnic minorities and those with disabilities. We find that sanction rates are higher in local authorities where more claimants are lone parents or live with a disability, and that this relationship has strengthened since the welfare reforms were introduced under the Conservative-led coalition. Failure to meet conditions of benefit receipt may disproportionately affect vulnerable groups.

Keywords: Conditionality, sanctions, jobseekers allowance, exclusion, disability.

\section{Introduction}

Access to welfare benefits has long been predicated on meeting certain conditions, such as being available for work (Hills, 2015). But recently, the conditions of entitlement have changed, becoming more stringent (Watts et al., 2014), and the consequences of failing to meet those conditions have become more severe. These changes have coincided with a doubling of the number of sanctions applied to Jobseeker's Allowance (JSA) claimants from a rate of 2.3 sanctions per 100 claimants per month in 2009/10 to 4.5 sanctions per 100 claimants in 2014/15.

In 2015, a Department of Work and Pensions (DWP) Select Committee heard evidence from frontline agencies documenting how sanctions disproportionately affect vulnerable groups (Work and Pensions Committee, 2015), concluding that intensified conditionality has led to 'some vulnerable individuals ... being "set up to fail"' (Work and Pensions Committee, 2015: 28). In this article, we conduct a novel quantitative analysis of sanction rates to explore this hypothesis directly, examining whether the removal of the rights of citizens to social security are being disproportionately applied to particular groups: the disabled, ethnic minorities and lone parents. 


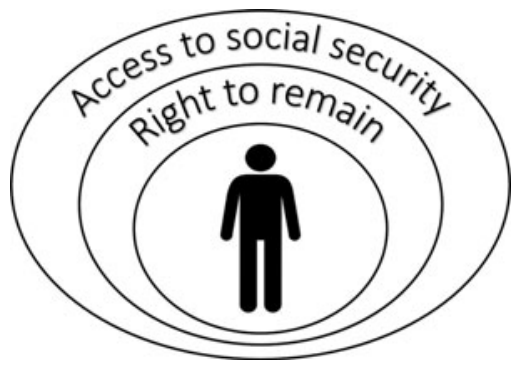

Figure 1. A layered conception of citizenship

\section{Citizenship and social security}

The rights of citizenship, according to Marshall (1950), can heuristically be split into three parts: civic, political, and social. Here, we explore how sanctions affect the social rights of citizenship, which entitles citizens to a 'modicum of economic welfare' and 'to live the life of a civilized being according to the standards prevailing in the society' (Marshall, 1950: 10-11).

The entitlements of citizens are often layered because eligibility to particular components of citizenship (e.g., civic, political, and social) can be predicated on different principles (Patrick and Fenney, 2015). Figure 1 illustrates this layering, showing how the full array of rights are available only to those who meet all the expectations of citizens pertaining to, for example, the right to remain and access to social security, whereas people who fail to meet certain conditions can be disentitled from some (but rarely all) of the rights of citizens. ${ }^{1}$

The layering of British citizenship is partly determined by policy decisions that define the expectations and entitlements of citizens (Tyler, 2013). Policy, of course, changes; and so governments can (suddenly) make it more difficult for some groups to obtain access to certain entitlements. Successive governments since the 1980s have done just this; redesigning policy to change the expectations of citizens seeking the social rights of citizenship. Those less able to meet these expectations have, as a consequence, become more precarious (Edmiston, 2014; Tyler, 2013).

Although beginning before 2010, this process has been particularly evident in the recent intensification of conditionality for people who are unemployed but deemed able to work (Watts et al., 2014; Webster, 2016). The Conservative-led coalition - building on reforms implemented under New Labour - adjusted the conditions for claiming JSA to address the problems (as the government saw them) of profligate public spending and welfare dependency (Hills, 2015).

Starting in 2010, the government introduced three major sets of reforms. First, a series of policy interventions moved people deemed able to work from Incapacity Benefit, Employment Support Allowance, or Income Support onto Jobseeker's Allowance (JSA) (DWP, 2014). Second, the conditions to obtain JSA became more stringent (Watts et al., 2014). The government introduced the Work Programme, requiring some claimants to participate in workfare to receive JSA. Introduced in 2013, the Claimant Commitment created a contractual obligation to perform certain actions in looking for work (such as attend all Jobcentre Plus appointments as scheduled and on-time, to spend thirty-five 
hours a week looking for work, and applying for a minimum number of jobs per week). Lastly, the penalties (sanctions) for failure to meet these new conditions became more severe (Adler, 2016). ${ }^{2}$ All of these reforms have sought to change the behaviour of citizens without directly addressing the obligations of the state to its citizens to provide work, suggesting these changes are intended, in part, to address the problem of welfare spending by activating citizens. To accomplish this, the government have shifted the expectations and entitlements of social citizenship.

\section{Sanctions as governmentality}

Designing policy to produce a particular kind of citizen is an example of governmentality, which is the processes or techniques through which the state attempts to alter the behaviour of citizens (Rose et al., 2006). Recent changes to conditionality and sanctions are examples of neoliberal governmentality, a particular form of governmentality characterised by 'permanent vigilance, activity, and intervention' (Foucault, 2008: 132). Neoliberal governmentality reconfigures citizenship by creating insecurity and anxiety as a means to motivate activity and change behaviour (Tyler, 2013); turning failed citizens into productive, active, valued citizens (Foucault, 2008).

The new conditionality regime articulates a state-dominated view of how the failed and the active citizen behave. In the specific context of JSA, an active citizen is willing and able to adhere to the Claimant Commitment and participate in the Work Programme. Failure to conform to the state's view of the active citizen entails stigma and financial penalties, thereby institutionalising this new norm of citizenship (Rose et al., 2006).

Key, however, is that this view assumes that JSA claimants are able to meet the Claimant Commitment. Yet, academics and frontline services have expressed concern that these new norms of citizenship are incongruent with the capabilities of some JSA claimants, particularly among those who have a limited understanding of English, or who are disabled or lone parents (Oakley, 2014; Johnsen, 2016). Data from a DWP evaluation suggested that between 40 and 50 per cent of Universal Credit claimants believed that at least some of the actions in the Claimant Commitment did not 'take account of personal circumstances' and were not 'achievable' (Adler, 2016). Moreover, in another study, two thirds of single parents were not aware there were 'flexibilities' that can allow the jobseeker to tailor conditionalities to their circumstances (Coleman and Riley, 2012); and many single parents do not receive the support they believe they need (Whitworth, 2013). Sanctions may be penalising people who are, in many cases, unable - not unwilling - to meet these new norms (Work and Pensions Committee, 2015). As a result, the obligations of this new citizen, created by this policy instrument, may disadvantage some groups of individuals more than others, removing the financial protections offered to those who have a different set of capabilities.

By establishing this new institutionalised norm, conditionality may be inadvertently but disproportionately excluding some groups from the entitlements of social citizenship. Levitas and colleagues defined social exclusion as the lack or denial of resources ... and the inability to participate in ... normal relationships and activities' (Levitas et al., 2007). If claimants are unable to meet the conditions of welfare receipt, resulting in a sanction, we suggest this may deepen the degree of social exclusion faced by vulnerable groups. First, the sanction removes income intended to ensure citizens have sufficient resources to 
meet their basic needs. Second, sanctions can lead to engaging in stigmatising behaviour, such as using foodbanks (Loopstra et al., 2015b).

Here, we explore whether there is any evidence to suggest that the practice of sanctioning may set up some groups to fail. We do so by drawing on a unique dataset matching sanction rates to the demographic composition of JSA claimants. We ask: is there evidence that groups less able to meet the conditions of social security receipt are more likely to experience sanctions, and thereby be excluded from some of the rights of social citizenship?

\section{Methods}

We constructed a novel longitudinal cross-local authority dataset to examine how variation in JSA claimant characteristics related to sanctioning rates for the period 2009/10-2014/15. Data on the size of the working age population and the monthly JSA claimant count for local authority districts and unitary authorities in England, Scotland and Wales were obtained from nomisweb. The monthly number of claimants aged eighteen to twenty-four and over sixty (excluding pensioners) were also collected, as well as the monthly number of claimants claiming for twelve months or more. We used these data to calculate monthly claimant rates per working age adult and the proportion of claimants who were young, older than sixty, and claiming for over twelve months. Monthly rates were then averaged over fiscal years.

We focused our analysis on three possible at-risk groups: disabled, lone parents and ethnic minorities. Informed by evidence from frontline services working with JSA claimants, these are groups who may be less able to meet the stringent requirements of the Claimant Commitment due to difficulty understanding requirements, restricted ability to make Jobcentre Plus appointments or possible discrimination within the workplace or Jobcentre Plus offices. To obtain detail on claimant characteristics, we acquired a special license to access local area identifiers for the Annual Population Survey (APS), available from the UK Data Archive, for 2008/09-2014/15. We used these data to calculate the proportion of JSA claimants in local authority areas who had disabilities, were lone parents and who were from an ethnic minority. Disability was defined as those who have long-term limiting health conditions. We also calculated the number of claimants who had National Qualifications Framework (NQF) level 4 education or above, measuring the level of educational attainment among claimants.

A limitation of using APS data to describe claimant characteristics is that sample sizes are very small for local authorities with small populations, resulting in some cases in too few claimants to reliably estimate the proportion with the characteristics of interest. Thus, we restricted our sample to only those local authorities that had sample sizes greater than 600 persons, reducing our sample from 2,625 to 1,205 local authority-years. In addition, in a number of local authority-years $(n=457)$, there were no claimants with one or more of the characteristics of interest (i.e. claimants with disabilities, lone parents, ethnic minorities, or with high levels of education). We treated these as zeros in our analysis. In reality, these values are underestimates arising from sampling error, as the true proportions of claimants with these characteristics are likely to be non-zero. We conducted sensitivity tests to observe how these assumptions affected our findings (see below).

Data on the number of sanctions applied to claimants each month were accessed from Stat-Xplore by local authorities (DWP, 2016). We used data on the number of adverse 
sanctions after any successful reviews, reconsiderations or appeals, reflecting only those decisions where claimants received a sanction that was applied and not appealed at a later time. We used claimant count data to calculate monthly rates of sanctions applied per claimant and averaged rates over fiscal years. For a specificity test, we also extracted detail on the number of sanctions where claimants had a disability, were lone parents or who were from an ethnic minority to test whether changes in the composition of JSA claimants were associated with reported sanctions applied to these groups.

\section{Statistical analysis}

To test our hypothesis, we examined local area sanction rates associated with local area claimant characteristics, as follows:

$$
\begin{aligned}
\text { Sanctions }_{\text {it }}= & \beta_{1} \text { Disability }_{\text {it }}+\beta_{2} \text { LoneParents }_{\text {it }} \\
& +\beta_{3} \text { EthnicMinority }_{\text {it }}+\beta_{4} \text { Education }_{i t}+\varepsilon_{i t}
\end{aligned}
$$

Here, $i$ is local authority and $t$ is year. Sanctions is the sanctioning rate, calculated as the number of adverse sanctions as a percentage of JSA claimants in local authorities. Disability, LoneParents, EthnicMinorities and Education refer to the percentage of claimants with each characteristic, respectively. $\varepsilon$ is the error term. Standard errors were clustered at the local authority level to reflect non-independence of the sampling. Lastly, we weighted our model estimates by the population of the local authority, giving greater credence to more reliable estimates of the socio-demographics of JSA claimants.

In a subsequent model, we adjusted for potential confounders. We added the proportion of claimants with claims for longer durations (twelve months or more), as vulnerable groups may claim for longer durations, which, in turn, can lead to being subject to greater conditions (e.g. mandatory work programmes). Thus, duration of claims could be one reason why sanction rates are associated with these claimant characteristics. We also controlled our models for age of claimants because these characteristics could potentially confound the relationships between characteristics of vulnerability and sanctioning. Namely, older claimants may be more likely to have disabilities, but less likely to be sanctioned on account of their age. Younger claimants are more likely to be sanctioned but less likely to have chronic health conditions (Work and Pensions Committee, 2015). Lastly, we also include local authority fixed effects, thereby controlling for unobserved differences across local authorities that are constant across this period.

Next, we tested whether observed associations were robust after accounting for features of the local labour market, which may explain both the characteristics of JSA claimants and the sanction rate. To do so, we first examined how the claimant rate in local authorities related to the sanction rate. Then, we adjusted our models for employment rates, economic inactivity rates, unemployment rates and the ratio of Jobcentre Plus vacancies to JSA claimants. The latter indicator provides a measure of jobcentre staff's knowledge of available work for claimants, while unemployment rates may influence perceptions of available local work among jobcentre staff (i.e. in places with low unemployment rates, jobcentre staff may perceive claimants to have more job opportunities).

We also examined whether the strength of relationships observed between claimant characteristics and sanctioning changed in the years following reforms to 
Table 1 Association between demographic characteristics of JSA claimants and the adverse sanction rate, 2008 to 2014

\begin{tabular}{lccc}
\hline \hline & \multicolumn{2}{c}{ Proportion of JSA claimants adversely sanctioned } \\
\cline { 2 - 4 } Variable & $(1)$ & $(2)$ & $(3)$ \\
\hline Proportion of JSA claimants & $0.032^{* *}$ & $0.015^{* *}$ & $0.0089^{* *}$ \\
who report a disability & $(0.0039)$ & $(0.0035)$ & $(0.0033)$ \\
Proportion of JSA claimants & $0.027^{* *}$ & $0.017^{* *}$ & $0.0066^{*}$ \\
$\quad$ who are lone parents & $(0.0045)$ & $(0.0037)$ & $(0.0032)$ \\
Proportion of JSA claimants & $0.0039^{*}$ & -0.0027 & $-0.0068^{*}$ \\
$\quad$ who are an ethnic minority & $(0.0019)$ & $(0.0030)$ & $(0.0028)$ \\
Proportion of JSA claimants & 0.0024 & 0.0029 & 0.0037 \\
that have a high level of & $(0.0038)$ & $(0.0035)$ & $(0.0031)$ \\
education (NQF level 4 or & & & \\
above) & & & $0.089^{* *}$ \\
Proportion of JSA claimants & - & $(0.0067)$ & $(0.0062)$ \\
$\quad$ claiming for Over 12 months & - & 0.11 & $-0.57^{* *}$ \\
Proportion of JSA claimants & - & $(0.067)$ & $(0.099)$ \\
$\quad$ aged 55-64 & - & -0.024 & $-0.17^{* *}$ \\
Proportion of JSA claimants & $\mathrm{N}$ & $\mathrm{N}$ & $(0.028)$ \\
$\quad$ aged 18-24 & $1.95^{* *}$ & $2.09^{* *}$ & $\mathrm{Y}$ \\
Local authority fixed-effects & $(0.16)$ & $(0.55)$ & $7.18^{* *}$ \\
Constant & 1205 & 1205 & $(0.94)$ \\
Observations & 0.14 & 0.35 & 1205 \\
$R^{2}$ & & 0.55 \\
\hline \hline
\end{tabular}

Notes: Standard errors in parentheses. All models include weighting by local authority size. Model 3 includes local authority fixed effects.

${ }^{*} p<0.05,{ }^{* *} p<0.01$

JSA conditionalities and accompanying sanctioning penalties. These changes occurred incrementally from mid-2011 to 2013. We hypothesised that these changes, cumulatively, would result in a stronger relationship between disadvantaged claimant characteristics and sanctioning outcomes in years following their implementation. To examine this hypothesis, we tested interactions between these characteristics with a dummy variable marking years before and after reforms (i.e. before 2012/13 vs. 2012/13 and after).

Descriptive statistics are reported in Web Appendix 1.

\section{Results}

Disability, lone parenthood, ethnic minority status, and sanctioning

The proportions of JSA claimants with disabilities and who were lone parents were positively related to the proportions of claimants who were sanctioned (Table 1). For every 1 percentage point increase in the proportion of claimants with disabilities, the rate of sanctions applied to claimants rose by 0.032 percentage points $(95 \% \mathrm{Cl}: 0.024$ to 0.040 ). Similarly, with every percentage point increase in the proportion of claimants 
who were single parents, the rate of sanctions among claimants rose by 0.027 percentage points (95\% Cl: 0.018 to 0.035$)$. We initially observed a weak positive association between sanction rates and the proportion of claimants from ethnic minority groups $(\beta=$ $0.0039,95 \% \mathrm{Cl}: 0.0001$ to 0.0077 ) but no clear association with the level of education of claimants.

Next we added the proportion of claimants claiming for more than twelve months and the age composition of claimants as well, and included local authority fixed effects (Table 1: Models 2 and 3). We observed higher rates of sanctioning in areas with a higher proportion of long-term claimants and in areas where more claimants were fifty-five years or older. But, even after including these additional controls, our two main findings were unchanged: the sanctioning rate increased as the proportion of disabled or lone parent JSA claimants in local authorities also increased.

\section{Local labour markets, sanctions and exclusion}

These findings were not explained by claimant rates in local authorities or local labour market conditions. The correlation coefficient between sanction rates and the claimant rate in local authorities was only 0.087, reinforcing that it is the characteristics of claimants (and not the claimant rate) that relates to sanctioning rates. Next we tested whether our results changed if we adjusted for labour market conditions, including adjusting for employment rates and the economic inactivity rate. The latter group may constitute the 'hidden unemployed'; those who are out of work but who are economically inactive because they have been unable to find employment for many years (Beatty and Fothergill, 2013). Our results remained largely unchanged (see Web Appendix 2). We then considered whether the perceived or real availability of work altered our findings. Again, our results were stable after accounting for these measures of local labour market conditions (see Web Appendix 3).

\section{Increasing exclusion after welfare reforms}

Next we examined whether the observed associations between sanctions and both the proportion of disabled and lone parent JSA claimants were stronger in the period following welfare reforms and sanction regime changes in 2012. Figure 2 highlights how, before these reforms, for every 1 percentage point increase in disabled claimants, the sanctioning rate increased by only 0.006 percentage points. However, in the period of reforms, this association became almost four times as strong, increasing by 0.016 percentage points. Similarly, the strength of association between lone parenthood and sanctioning more than doubled in this period compared to prior to 2013 (see Web Appendix 4).

\section{Sensitivity analyses}

In the web appendix, we include details of a series of sensitivity checks to ensure our model was robust to alternate specifications. These include: (1) adjusting for time dummies; (2) including all local authorities irrespective of sample size; (3) restricting our sample to only local authorities with non-zero values on the key socio-demographics; (4) excluding local authorities where estimates suggested all claimants were, for example, 

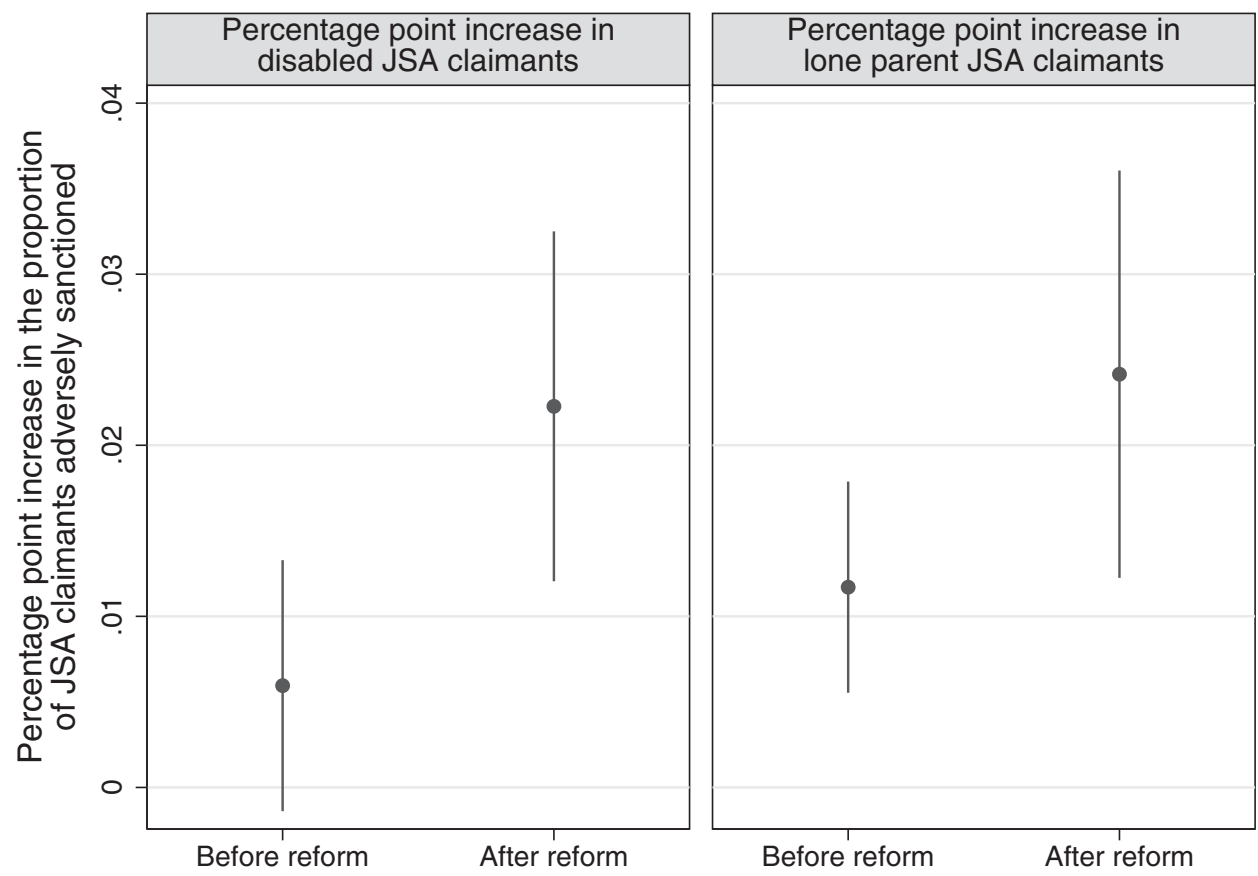

Figure 2. Association between disability and long parents with adverse sanctions before and after the change in sanction regime

Notes: Full model is reported in web appendix 2. Vertical bars are $95 \%$ confidence intervals. All models include weighting by local authority size.

disabled; (5) removing weights; (6) weighting by the Annual Population Survey sample size; and (7) using sanction referrals as the outcome. In all cases, our results remain unchanged (see Web Appendices 5-11 for results).

One puzzle posed by our results is the seeming difference between our regression estimates and the aggregate-level trends for lone parents. Across Great Britain, in any given month, lone parents are sanctioned at a lower rate than non-lone parent claimants (DWP, 2016), suggesting that sanction rates should fall as the proportion of lone parent claimants rises. Digging into this relationship in more detail, we find the aggregate data show that as the monthly single parent claimant rate increases so too does the monthly sanctioning rate among single parents (and total sanctioning rate as well). This association holds even after we adjust for different possible time trends. Next, we looked more closely at the local authority-level data, testing whether the association between the sanction rate and the proportion of lone parent claimants varies across local authorities by the single parent claimant rate. We find that the association between the sanction rate and lone parents is negative (or flat) in local authorities where there is a low proportion of lone parent claimants. But this same relationship is positive in local authorities where the proportion of single parent claimants is high (>10 per cent). In short, our findings from our cross-local area analyses are not inconsistent with the aggregate-level data. They suggest that the rate of sanctions per single parent claimant at the aggregate level may mask important variations across local authorities; which may lower the average sanction 
rate among single parents at the aggregate level (For more details of these analyses, see Web Appendix 12).

Lastly, we tested whether claimant characteristics relate most strongly to the count of sanctions applied to these specific groups (i.e. the disabled and lone parents). We found more disabled people were sanctioned (as a proportion of total claimants) when there were a larger proportion of disabled claimants (Web Appendix 13). We also found similar results for lone parents. These findings give greater specificity to the main finding of this article; namely that disproportionately higher sanction rates are driven by disproportionately higher rates of sanctions among disabled and lone parent claimants.

\section{Discussion}

The conditionality regime applied to JSA claimants assumes some unemployed people are passive recipients of welfare and that stricter conditions, coupled with (the threat of) sanctions, will motivate passive recipients to become active jobseekers (Hills, 2015). Yet, both frontline services and the Work and Pensions Committee have observed that there remains a danger that some vulnerable individuals are being "set up to fail" [by the new conditionality regime]' (Work and Pensions Committee, 2015: 28).

Indeed, in our quantitative cross-local authority analyses, we observed that conditionality seems to be inadvertently setting up some vulnerable groups to fail. Sanction rates appear to be higher in areas where there are more disabled and lone parent JSA claimants. Sanction rates were not, however, associated with ethnic minority claimants. Conditionality appears to disadvantage those with ill health, physical limitations, or uncertain family commitments. These penalties may exclude these individuals from some of the entitlements of social citizenship: not because they are unwilling but because they are, in many cases, unable to live up to these new norms of productive and active citizenship.

Changes to welfare conditionality under the Conservative-led coalition government may have made things worse, deepening the disadvantage faced by disabled and lone parent JSA claimants. After the 2012/13 reforms, sanction rates were even more closely associated with rates of disability and lone parenthood amongst claimants. This deepening disadvantage may be linked with the Work Programme and the Claimant Commitment, which have potentially increased the gap between the expectations of the vaunted active citizen and the capabilities of some JSA claimants. All of these interventions in the labour market have been concentrated on the individual rather than on the number of suitable vacancies for disabled and lone parent JSA claimants. The consequences of this exclusion could be severe for the material well-being of disadvantaged claimants, as shown by the link between sanctioning and foodbank use (Loopstra et al., 2015b) and evidence of conditionality causing destitution (Dwyer and Bright, 2016).

Our results also highlight how the layered nature of citizenship is shaped by policy processes (Tyler, 2013). Conditionality and sanctions both serve to create institutionalised norms of citizenship through the enactment of neoliberal governmentality (Rose et al., 2006); which seeks to change behaviour through exposing (or threatening to expose) people to precariousness. Further, these policies also alter the nature of social citizenship, redrawing the boundaries between the deserving and undeserving poor. Our results problematise both this deservingness distinction and this layered notion of citizenship, drawing attention to how changes to conditionality have encouraged 
the unemployed to become more active and productive. To achieve this, these reforms have redefined active citizenship and, in the process, may have created 'failed citizens', i.e., those who are less able to follow these procedures and meet these expectations, potentially leading to even greater social exclusion for lone parents and those living with disability.

There are important limitations to our study. First, the data we used to measure the socio-demographic characteristics rely on small sample sizes and may include measurement error. However, we found our results were stable when we removed extreme observations and when we included or excluded local authorities with the smallest samples. Second, some of the measures we used do not precisely capture the sources of conflict with the new conditionality regime (e.g., language barriers faced by some members of minority communities). Similarly, the disability measure from the Annual Population Survey is subjective, introducing measurement error into our models. More detailed measures are needed to explore how claimant characteristics associate with inability to meet claimant commitments and how these associate with sanction rates. Third, our analysis cannot reveal whether those people sanctioned are lone parents or individuals with disabilities (i.e., the ecological fallacy). However, our analysis builds upon qualitative research which suggests the sanctions process may disadvantage these groups, thus there is theoretical consistency between our aggregate-level findings and the individual-level findings reported elsewhere. Future work will be needed to explore these important and unresolved issues; verifying whether these associations are consistent with the individual-level data and whether these relationships are, in fact, causal.

Despite these limitations, our work has a number of policy implications. The DWP does provide Vulnerability Guidance to Jobcentre Plus staff (Work and Pensions Committee, 2015), outlining the personal circumstances and life events staff should consider when making a judgement on whether claimants may need 'additional support to enable them to access DWP benefits'. Yet, this guidance continues to emphasise that the aim for individuals is to follow standard customer journeys, and so concerns remain about the lack of guidance on what expectations are appropriate for vulnerable groups (Tyler, 2013). Our evidence reinforces these concerns, highlighting how claimant characteristics may influence the ability of claimants to comply with welfare conditionalities.

From a pragmatic viewpoint, policymakers may ask: does conditionality work? To date, in the UK, there is little evidence that recent changes to conditionality have improved the quality of job searches (Webster, 2016). Sanctions may have increased off-flow from JSA but without increasing employment (Loopstra et al., 2015a). Moreover, there is little evidence that sanctions have changed the character or behaviour of JSA claimants, with many people receiving multiple sanctions (Webster, 2016). This is unsurprising if the background economic conditions that enable people to find suitable employment are not also addressed. Sanctions may increase demand for paid work, but if there is no concurrent intervention in the supply of work, sanctions will only lead to financial insecurity.

The Work and Pensions Select Committee's report on sanctions observed that the conditionality regime may have inadvertently set up some vulnerable groups to fail. We have found that sanction rates are higher in areas where more claimants are disabled or lone parents (i.e., groups that are potentially less able to comply with welfare conditions). This suggests that the procedures of welfare conditionality may be biased against those who are already at risk of social exclusion. 


\section{Notes}

1 Some non-citizens do receive financial support from the state, for example asylum seekers. However, asylum seekers are not citizens and do not have access to social security. In fact, until they obtain 'indefinite leave to remain' they are have 'no recourse to public funds', meaning they are not entitled to Jobseeker's Allowance. In such circumstances, people in this situation turn to their local authorities for help but there is no statutory guidance issued to local authorities on their duties to support people with 'no recourse to public funds'.

2 After the reforms, the minimum sanction period became four weeks for minor offences and thirteen weeks for more serious offences. In rare cases, claimants could be excluded for as long as 156 weeks (three years).

\section{Supplementary material}

To view supplementary material for this article, please visit http://doi.org/10.1017/ S1474746416000646.

\section{References}

Adler, M. (2016) 'A new Leviathan: benefit sanctions in the twenty first century', Journal of Law and Society, 43, 195-27.

Beatty, C. and Fothergill, S. (2013) 'Disability benefits in the UK: an issue of health or jobs?', in D. Houston and C. Lindsay (eds.), Disability Benefits and Employment Policy: Fit for Work, Fit for Purpose? London: Palgrave Macmillan.

Coleman, N. and Riley, T. (2012) Lone Parent Obligations: Following Lone Parents', Journeys from Benefits to Work, London: Department for Work and Pensions.

Department for Work and Pensions (DWP) (2014) Jobseeker's Allowance and Flexibilities for Lone Parents: Factsheet, London.

Department for Work and Pensions (DWP) (2016) 'Stat-Xplore', Department for Work and Pensions.

Dwyer, P. and Bright, J. (2016) 'First wave findings: overview', Welfare Conditionality: Sanctions, Support and Behaviour Change. http://www.welfareconditionality.ac.uk/wp-content/uploads/2016/05/ WelCond-findings-Overview-May16.pdf.

Edmiston, D. (2014) 'Social security privatisation: a means to whose end?' People Place and Policy, 8, 2, 113-28.

Foucault, M. (2008) The Birth of Biopolitics: Lectures at the College de France, 1978-79 (M. Senellart, trans.), Basingstoke: Palgrave Macmillan.

Hills, J. (2015) Good Times, Bad Times: The Welfare Myth of Them and Us, London: Policy Press.

Johnsen, S. (2016) 'First wave findings: lone parents', Welfare Conditionality: Sanctions, Support and Behaviour Change.

Levitas, R., Pantazis, C., Fahmy, E., Gordon, D., Lloyd, E. and Patsios, D. (2007) The Multi-Dimensional Analysis of Social Exclusion, Bristol: Social Exclusion Unit. http://www.welfareconditionality.ac.uk/ wp-content/uploads/2016/05/WelCond-findings-lone-parents-May16.pdf.

Loopstra, R., Reeves, A., McKee, M. and Stuckler, D. (2015a) 'Do punitive approaches to unemployment benefit recipients increase welfare exit and employment? A cross-area analysis of UK sanctioning reforms', Oxford Sociology Working Paper Series.

Loopstra, R., Reeves, A., Taylor-Robinson, D., Barr, B., McKee, M. and Stuckler, D. (2015b) 'Austerity, sanctions, and the rise of food banks in the UK', British Medical Journal, 350, h1775. doi:10.1136/bmj.h1775.

Marshall, T. H. (1950) Citizenship and Social Class, and Other Essays, Cambridge: Cambridge University Press. 
Oakley, M. (2014) Independent Review of the Operation of Jobseeker's Allowance Sanctions Validated by the Jobseekers Act 2013, London: The Stationary Office.

Patrick, R. and Fenney, D. (2015) 'Disabled people, conditionality, and civic minimum in Britain: reflections from qualitative research', in C. Grover and L. Piggott (eds.), Disabled People, Work, and Welfare: Is Employment Really the Answer? Bristol: Policy Press, 25-42.

Rose, N., O'Malley, P. and Valverde, M. (2006) 'Governmentality', Annual Review of Law and Social Science, 2, 83-104.

Tyler, I. (2013) Revolting Subjects: Social Abjection and Resistance in Neoliberal Britain, London: Zed Books.

Watts, B., Fitzpatrick, S., Bramley, G. and Watkins, D. (2014) Welfare Sanctions and Conditionality in the UK, York: Joseph Rowntree Foundation.

Webster, D. (2016) 'Benefit sanctions have failed: a comprehensive review is needed', LSE British Politics and Policy blog, http://blogs.Ise.ac.uk/politicsandpolicy/benefit-sanctions-have-failed-acomprehensive-review-is-needed/.

Whitworth, A. (2013) Tailor Made? Single Parents' Experiences of Employment Support from Jobcentre Plus and the Work Programme, London: Gingerbread.

Work and Pensions Committee (2015) Benefit Sanctions Policy Beyond the Oakley Review, London: Department for Work and Pensions. 